\title{
点击反应在糖聚肽及其类似物合成中的应用
}

\author{
王 昭 $a, c$ 郝凌云 $a$ 张小娟 $a$ 盛瑞隆*,,$c$ \\ ( ${ }^{a}$ 金陵科技学院材料工程学院 南京市视光材料与技术重点实验室 南京 211169)
}

( ${ }^{b}$ CQM-Centro de Química da Madeira, Universidade da Madeira, Campus da Penteada, Funchal, 9000-390 Portugal)

( ${ }^{c}$ 中国科学院上海有机化学研究所 上海 200032)

\begin{abstract}
摘要 糖聚肽是一类由聚肽/聚氨基酸与糖类化合物共价相连构成的高分子化合物, 因其良好的生物相容性及独特的 生物学性能, 在自组装、组织工程、药物输送等领域均显示出广泛的应用前景, 成为近年来蓬勃发展的热点领域. 高效 合成结构规整可控的糖聚肽是该领域的热点和难点. 点击化学的快速发展为糖聚肽的合成提供了高效便捷的途径. 系 统综述了点击反应在糖聚肽两种合成策略中的应用——通过聚合后修饰法将糖分子引入到聚氨基酸前体侧链上以及 对糖苷化的 $\alpha$-氨基酸- $N$-羧酸酐 (glyco-NCA) “可点击” 化学单体的开环聚合反应，同时也总结了通过点击反应将含糖 功能基元化学偶联到聚氨基酸链末端合成糖聚肽类似物的策略, 并对其优缺点和发展方向进行了简要讨论.
\end{abstract}

关键词＼cjkstart糖聚肽；点击反应；聚合后修饰；开环聚合

\section{Advances of "Click" Reaction Approach in Glycopolypeptide Synthesis}

\author{
Wang, Zhao ${ }^{a, c}$ Hao, Lingyun ${ }^{a} \quad$ Zhang, Xiaojuan $^{a} \quad$ Sheng, Ruilong $^{*, b, c}$ \\ ( ${ }^{a}$ School of Material Engineering, Jinling Institute of Technology, Nanjing 211169, China) \\ ( ${ }^{b}$ CQM-Centro de Química da Madeira, Universidade da Madeira, Campus da Penteada, 9000-390 Funchal, Portugal) \\ ( ${ }^{c}$ Shanghai Institute of Organic Chemistry, Chinese Academy of Sciences, Shanghai 200032, China)
}

\begin{abstract}
Synthetic glycopolypeptides, as analogues of natural glycoproteins, are an emerging class of bioinspired polymers with excellent biocompatibility. They can mimic the structure and functions of natural glycoproteins, and show great potential for biological applications, such as biomolecular recognition, drug/gene delivery, cell adhesion and targeting, as well as cell culture and tissue engineering. Nevertheless, the efficient and lab/pilot scale preparation of well-defined and tunable glycopolypeptides with complex polymer structures, has been a challenging field until now. The fast development of "Click" chemistry/reaction offers versatile and powerful tools for the synthesis of glycopolypeptides. The state of arts for the development of new "Click" synthetic strategies and methods in the preparation of glycopolypeptides, mainly including post-polymerization glycosylation of synthetic polypeptides and ring-opening polymerization of glycosylated $N$-carboxyanhydride (glyco-NCA) is reviewed. The pros and cons of current developments for the synthesis of glycopolypeptide analogues and their future perspectives are also stated and discussed.
\end{abstract}

Keywords glycopolypeptide; "Click" reaction; post-polymerization glycosylation; ring-opening polymerization

糖作为生物体的基本构建砌块和储能单元，以糖缀 合物的形态参与许多重要的生命过程 ${ }^{[1 \sim 5]}$. 其中, 糖蛋 白在细胞信号识别、神经调控、信息传递及免疫调节等
生命活动中扮演着重要角色. 糖肽是由糖基与氨基酸或 多肽链共价相连形成的缀合物，具有与糖蛋白相似的多 种生物功能，同时又不具有糖蛋白巨大的分子量和复杂

\footnotetext{
* Corresponding author. E-mail: ruilong.sheng@staff.uma.pt

Received March 21, 2019; revised April 19, 2019; published online May 6, 2019.

Project supported by the National Natural Science Foundation of China (No. 21372251), the Research Initiation Fund for High-level Talents of Jinling University of Science and Technology (No. jit-b-201828), the Fundação para a Ciência e a Tecnologia (No. PEst-OE/QUI/ UI0674/2019), the Reforço do Investimento em Equipamentos e Infraestruturas Científicas na RAM (No. M1420-01-0145-FEDER-000008), and the Sub Topic 2017-ISG-003 of Agência Regional para o Desenvolvimento da Investigação Tecnologia e Inovação (No. M1420-01-0145-FEDER-000005).

国家自然科学基金(No. 21372251)、金陵科技学院高层次人才科研启动基金(No. jit-b-201828)、葡萄牙科学技术基金(No. PEst-OE/QUI/UI0674/2019)、 科学仪器和基础设备专项基金(No. M1420-01-0145-FEDER-000008)、区域研究技术创新基金(No. M1420-01-0145-FEDER-000005)子课题 2017-ISG003 资助项目
} 
的结构, 因而糖肽作为研究糖蛋白的重要模型引起了人 们的广泛关注 ${ }^{[6]}$. 目前, 采用固相合成法、选择性化学修 饰法、酶催化糖基化法以及生物半合成法等有机化学合 成手段构建天然糖蛋白/糖肽类似物的方法, 均存在合 成步骤繁琐、产率较低等缺点, 限制了其进一步的发展 和应用. 近些年, 有机合成及聚合反应技术的发展为人 工合成糖蛋白/糖肽类似物提供了新的思路和手段. 将 聚肽/聚氨基酸与糖类化合物偶联制备的糖聚肽, 作为 天然糖蛋白/糖肽的合成类似物，其具有分子结构规整、 制备简单、易于设计和结构调控等优势, 为糖蛋白/糖肽 活性与构效关系的研究提供了基础, 已发展成为探索、 研究并阐明糖蛋白相关科学问题的有力工具. 同时, 糖 聚肽由于具有良好的生物相容性及独特的生物学性能, 在生物诊断、组织工程、细胞培养、药物输送等领域均 显示出广泛的应用前景 ${ }^{[7 \sim 9]}$.

到目前为止, 糖聚肽合成的研究已有 20 多年历史, 且在最近几年呈现出蓬勃发展的趋势, 但大量制备结构 规整的糖聚肽仍存在一定困难, 从而限制了糖聚肽在材 料及生物医药领域的应用. 点击化学(“Click” chemistry) 具有高效、快速, 高选择性、反应条件温和及立体选择 性好等优点, 在材料制备、药物合成等领域均得到了广 泛应用 ${ }^{[10,11]}$. 除了传统的铜催化的叠氮/炔的 1,3-偶极环 加成反应外, 目前颈基/烯、統基/炔、統基/马来酰亚胺、 Diels-Alder 以及卤代物与氮氧自由基偶联等新型点击 反应也得到蓬勃发展, 这些合成技术为糖聚肽及其类似 物的制备提供了便捷手段. 本文对近些年点击反应在糖 聚肽及其类似物合成中的应用进行了综述, 并对合成策 略进行了简述与评价.

\section{1 点击化学}

点击化学(“Click” chemistry)是由美国著名的化学 家 Sharpless 于 2001 年首次提出的 ${ }^{[2]}$, 它是继组合化学 之后又一具有颠覆性的合成技术，以其反应简单、快速、 高效等优点得到化学研究者的广泛青睐. 其中, 铜催化 的叠氮一炔 1,3-偶极环加成反应(copper-catalyzed azidealkyne cycloaddition, CuAAC) 是其代表性反应 ${ }^{[13,14]}$. 近 些年, 无金属催化的绿色点击反应更是成为研究的热 点, 被成功应用于聚合物制备、药物合成、蛋白质组学 和材料科学等领域 ${ }^{[15,16]}$.

目前点击反应的主要类型有 ${ }^{[17]}$ : (1) $\mathrm{Cu}(\mathrm{I})$ 催化的叠 氮与炔基反应生成 1,2,3-三唑五元环的反应 $(\mathrm{CuAAC})$; (2)环张力促进的叠氮与环炔的环加成反应 (strainpromoted cycloaddition of alkynes and azides, SPAAC); (3) 共轭双烯与亲双烯体的 Diels-Alder (D-A)环加成反 应; (4)巯基与各类官能团之间的反应，包括巯基-烯/炔
(Thiol-ene/yne)化学反应、統基-卤素取代反应、統基环氧反应以及颈基和异氭酸酯的反应等(Scheme 1). $\mathrm{CuAAC}$ 反应可以在多种质子和非质子溶剂中进行, 并 且不受其它官能团的影响, 是研究最早且应用最广的点 击反应类型. 该反应采用 $\mathrm{Cu}(\mathrm{I})$ 为催化剂, 也可以通过 $\mathrm{Cu}(\mathrm{II})$ 或者 $\mathrm{Cu}(0)$ 在反应过程中原位还原/氧化制备. 但 是, 使用铜盐作为催化剂, 后处理较为繁琐, 且产物中 残留的部分很难去除干净，限制了其在药物合成和生物 医药领域的应用. 随后，科研工作者经过探索研究发现， 环炔与叠氮的反应不需要金属催化剂, 仅依靠环炔的环 张力即可促进两官能团之间的反应。该反应速率虽然没 有 $\mathrm{CuAAC}$ 高, 但可以通过在环炔中引入强吸电子基团 (如氟原子等)来改变环张力, 加速反应的进行. SPAAC 的发展为生物体内蛋白质的苂光标记、分子示踪等提供

(a)

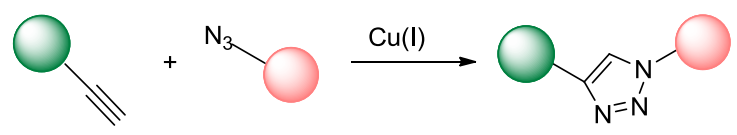

(b)

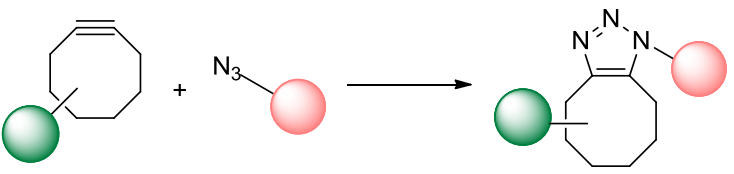

(c)
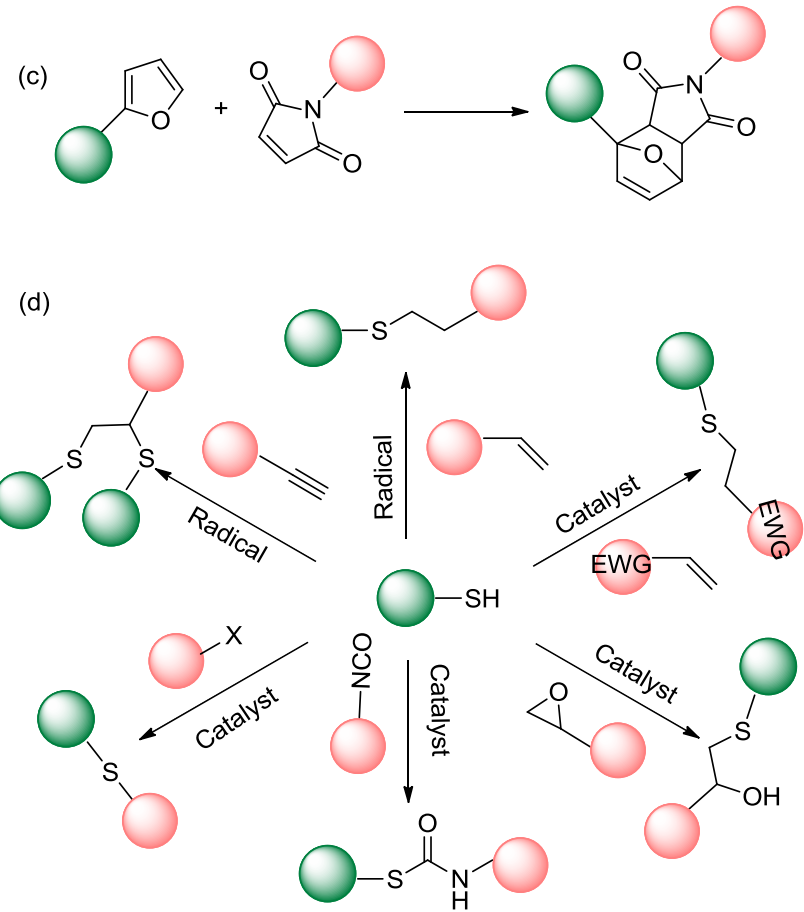

图式 1 常见点击反应类型示意图

Scheme 1 Schematic illustrations to show the typical "Click" reactions

(a) $\mathrm{Cu}(\mathrm{I})$-catalyzed cycloaddition of alkynes and azides (CuAAC), (b) strain-promoted cycloaddition of alkynes and azides (SPAAC), (c) Diels-Alder reaction and (d) thiol-involved reactions 
了新途径. D-A 环加成反应是指共轭双烯(diene)和亲双 烯体(dienophile)之间进行 [4+2]环加成反应形成稳定的 六元环化合物的反应. 该反应通常在较温和的条件下进 行, 一般不需要催化剂, 且反应进行到一定温度时可以 发生逆反应，应用于聚合物制备中，不仅有利于聚合物 的降解、回收和利用, 还可以用于构建化学键动态变化 的功能聚合物. 颈基与各类官能团的反应分为两大 类 ${ }^{[18]}$ : 一类是自由基加成反应, 包括颈基-烯 (Thiolene)和颈基-炔(Thiol-yne)的自由基加成反应; 另一类是 亲核加成反应, 包括巯基与环氧、异氧酸酯、卤素和缺 电子双键的迈克尔加成反应. 其中, 颈基-烯/炔化学反 应是近年来发展出的一类新型的点击反应, 一般通过加 热或紫外光照射产生自由基从而引发反应. 该反应便 捷、快速、立体选择性好, 可以在无金属催化剂和无溶 剂的条件下进行, 被认为是最有发展前景的无金属催化 点击反应 ${ }^{[19,20]}$.

由于点击反应效率高(产率一般高于 $90 \%$ ), 反应条 件温和, 催化剂高效稳定, 且所用单体中官能团均可以 通过简单温和的化学反应转化得到, 因而符合聚合反应 的要求, 被广泛应用于各种拓扑结构聚合物(包括线形、 刷形、星形、环状及树枝状大分子等)材料的制备当中. 除线形聚合物以外的拓扑结构聚合物都具有比较特殊 的性质, 如溶解性好、粘度低、热稳定性高和可修饰官 能团位点多, 且溶液自组装行为复杂, 因而在超分子与 自组装领域、生物医药等领域均有广阔的应用前景, 日 益受到大家的重视. 相关的合成方法及应用进展已有综 述报道 ${ }^{[21 ~ 32]}$, 在此不再赘述.

\section{2 点击反应在糖聚肽及其类似物合成中的应用}

糖聚肽(glycopolypeptides), 即糖苷化合成的聚氨基 酸/多肽, 严格意义上是指含有侧挂糖基元的聚氨基酸/ 多肽. 另外, 聚氨基酸/多肽与天然多糖或糖聚合物(采 用化学合成方法制备的含有侧挂糖基元的高分子化合 物)的化学偶联物, 包括线性、树枝状等各种拓扑结构的 合成聚合物统称为糖聚肽类似物 ${ }^{[33]}$. 由于该领域最近
几年才有较大发展, 尚未形成统一的表述, 因此, 很多 文献中不严格区分糖聚肽和糖聚肽类似物。

糖聚肽作为天然糖蛋白的合成类似物, 与糖蛋白相 比，具有制备简单、结构规整、易于批量化生产等优点. 人工合成糖聚肽不仅有助于理解天然糖蛋白的物理化 学性质及生物学特性, 同时为糖蛋白结构与功能之间构 效关系的研究提供了模型 ${ }^{[8]}$ (图 1). 糖聚肽高分子中聚氨 基酸骨架具有良好的生物可降解性, 并依据分子结构的 不同显示出 $\alpha$-螺旋、 $\beta$-折叠等二级结构, 有利于通过自 组装形成丰富形貌的聚集体 ${ }^{[34,35]}$. 另外, 已有大量研究 表明, 糖缀合物是重要的生物信息分子, 在许多生理和 病理过程中起着至关重要的作用, 并可通过与蛋白质的 特异性识别, 实现生物信息的有效传递 ${ }^{[4,36]}$. 将糖分子 偶联到聚氨基酸侧链或末端, 可赋予糖聚肽高分子良好 的亲水性和生物相容性, 以及生物分子识别和细胞粘附 特性等. 糖聚肽高分子自组装体系因其具有能仿生模拟 表面含糖缀合物的细胞或细胞器结构的特性而引起了 科研工作者深入的研究和探索. Lecommandoux 等 ${ }^{[37]}$ 合 成的葡聚糖和聚 $(\gamma$-谷氨酸 $L$ 芐酯)(PBLG)的嵌段共聚物 (dextran- $b-\mathrm{PBLG}$ )在水溶液中自组装成了类 “病毒衣壳” 结构的囊泡组装体; 糖基化聚(炔丙基甘氨酸)为亲水链 段、PBLG 为疏水链段的两亲糖聚肽(PBLG- $b$-PGG)依据 亲疏水链段比例的不同，在水溶液中自组装形成胶束、 囊泡或蠕虫状聚集体, 且不同形貌聚集体均可特异性识 别凝集素 $\mathrm{RCA}_{120}{ }^{[38]}$. Deming 等 ${ }^{[39]}$ 则研究了糖聚肽高分 子的二级结构对自组装体的影响, 结果发现, 在具有相 同疏水链结构的情况下, 亲水的糖聚肽嵌段若为无规结 构, 则自组装成囊泡结构聚集体, 若为 $\alpha$-螺旋结构, 则 形成无规则片状组装体. 另外, 含糖聚肽的两亲杂化高 分子也被应用于程序化分级自组装的研究及各种丰富 形貌自组装聚集体的制备当中 ${ }^{[40 \sim 43]}$. 另一方面, 糖聚肽 具有良好的生物相容性和独特的生理学性能, 在靶向药 物输送、细胞组织培养、生物成像等领域均获得广泛关 注. Wenz 等 ${ }^{[44]}$ 合成了一种具有荧光分子标记的半乳糖 侧挂修饰的聚赖氨酸, 并发现其具有靶向识别 $\mathrm{T}$ 淋巴细

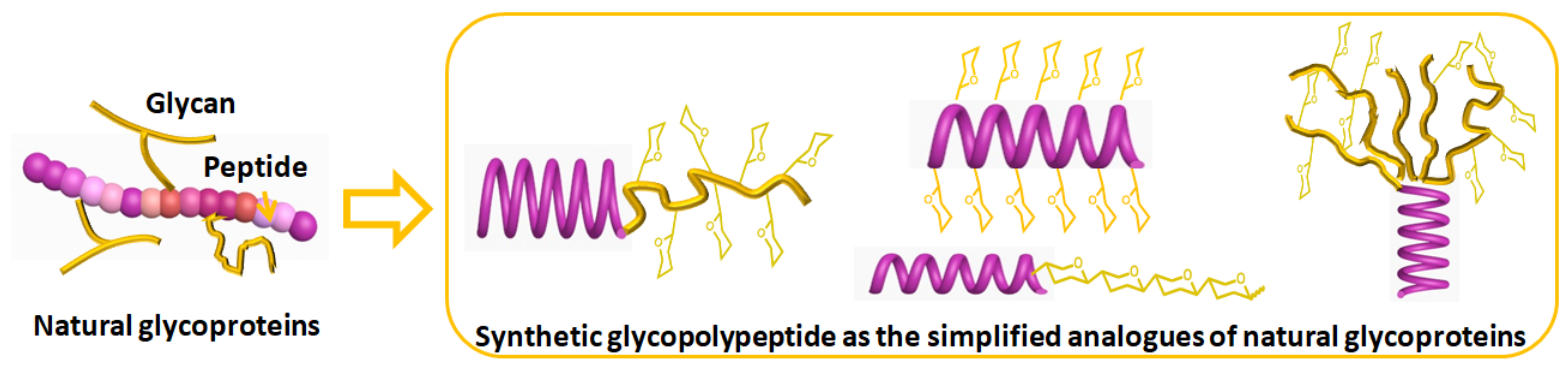

图 1 合成糖聚肽作为天然糖蛋白的仿生类似物 ${ }^{[8]}$

Figure 1 Synthetic glycopolypeptides as biomimetic analogues of natural glycoproteins 
胞表面的 L 选择素 CD26L 的能力. Chen 等 ${ }^{[45]}$ 制备的糖 聚肽 PPLG- $b$-PLGA 溶液自组装形成纳米胶束, 高效同 步负载抗肿瘤药物阿霉素 $(\mathrm{DOX})$; 该复合胶束具有 $\mathrm{pH}$ 响应性药物释放特性, 且能特异性靶向 HepG2 肝癌细 胞. 同时, 其制备所得 PPLG- $g$-Man/HPPA 共聚物, 通过 溶液中酶催化的交联反应生成可注射(injectable)糖聚肽 凝胶, 有望应用作为软骨组织工程中的三维仿生支 架 ${ }^{[46]}$. 除此之外, 合成糖聚肽作为基因输送载体 ${ }^{[47]}$ 、细 胞穿透材料 ${ }^{[48]}$ 、细胞的选择性吸附 ${ }^{[49]}$ 及活细胞膜的定点 修饰材料 ${ }^{[50]}$ 等均有相关应用报道. 糖聚肽的应用领域 在图 2 中表示.

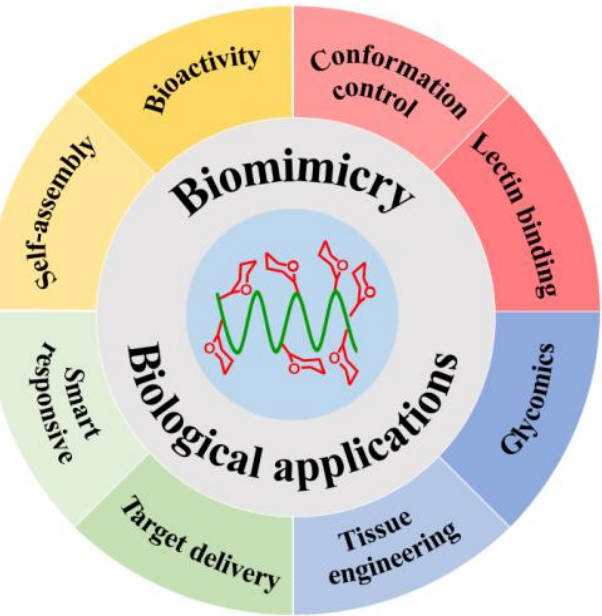

图 2 合成糖聚肽及其类似物在生物医药领域方面的应用

Figure 2 Biomedical applications for the synthesized glycopolypeptides and their analogues

糖聚肽在各个领域的应用也推动了科研工作者对 其合成制备方法的深入研究. 目前, 糖聚肽的合成方法
主要有两种: (1)首先制备功能化的聚氨基酸前体，再通 过聚合后修饰法将糖分子引入到聚氨基酸侧链上; (2)首 先合成糖苷化的 $\alpha$-氨基酸- $N$-羧酸酐 (glyco-NCA)单体, 再通过 NCA 开环聚合高效制备结构规整的糖聚肽. 另 外, 也可以直接将含糖基元化学偶联到聚氨基酸链末端 合成糖聚肽类似物，示意图如图 3 所示 ${ }^{[9,51]}$.

\section{1 利用点击反应在聚氨基酸侧链键合糖分子}

人工合成聚氨基酸作为天然蛋白质或多肽的合成 类似物，具有优异的生物相容性和生物可降解性，几十 年前已被作为结构材料使用, 最近十几年随着生物材料 的兴起而呈现出蓬勃发展的趋势, 被广泛应用于构筑精 确有序的纳米组装体及作为基因/药物输送载体 ${ }^{[52]}$. 聚 氨基酸的合成方法主要包括生物合成法、固相合成法以 及 $\alpha$-氨基酸- $N$-羧酸酐 $(\alpha$-carboxyanhydrides, NCA)开环 聚合法. 其中, NCA 开环聚合法具有操作简单、成本低、 产率高、无消旋，且聚合物分子量及分子量分布可控等 优点, 目前已成为聚氨基酸制备的主要方法 ${ }^{[53]}$. 该方法 通常是将 $\alpha$-氨基酸与(三)光气反应生成 $\alpha$-氨基酸- $N$-羧 酸酐单体, 再通过亲核试剂或者有机碱(最为常见的是 伯胺和醇盐负离子)及过渡金属配合物等引发 NCA 单体 开环聚合，高效可控制备得到结构规整的聚氨基酸 (Scheme 2). 同时，该方法可以进一步制备嵌段、接枝及 环状功能氨基酸聚合物. Deming 等 ${ }^{[53 \sim 62]}$ 在该领域做出 了许多开创性的工作, 并对 NCA 的活性/可控催化体系 进行了较为深入的探索和有效的改进. 经过 60 多年的 发展, 到目前为止, 已有近 200 种不同的天然或非天然 的 NCA 单体被制备出来, 用于聚氨基酸的合成. 具体 合成方法及聚合物的应用可参见相关综述报导 ${ }^{[63 ~ 72]}$. (a)

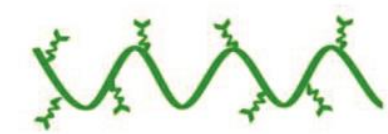

Polypeptide

(b)

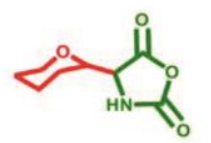

Glycosylated NCA

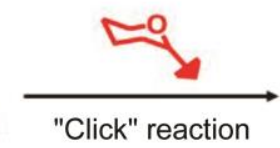

"Click" reaction

of
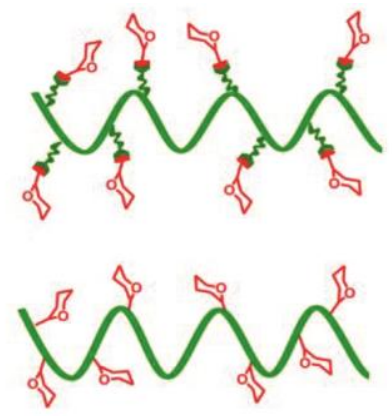

(c)

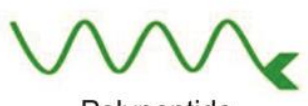

Polypeptide
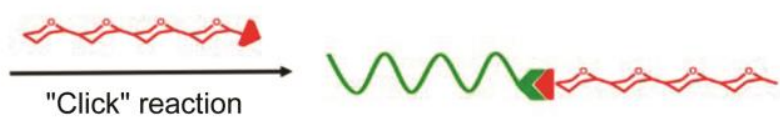

图 3 糖聚肽的制备策略示意图

Figure 3 Synthetic strategies of glycopolypeptides

(a) Post-polymerization glycosylation of synthetic polypeptides, (b) polymerization of glycosylated $N$-carboxyanhydride (glycol-NCA) and (c) glycosylation at the end extremity of polypeptide 


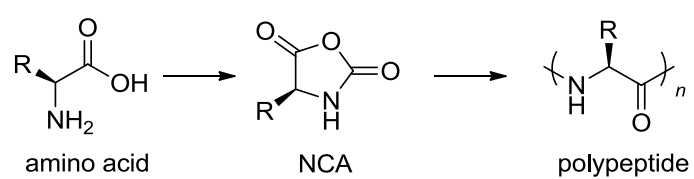

图式 $2 \mathrm{NCA}$ 开环聚合法合成聚肽/氨基酸

Scheme 2 Synthesis of polypeptides via ROP of NCA

基于已有的聚氨基酸高分子骨架, 研究者首先联想 到将糖基元通过化学偶联策略接枝到聚氨基酸侧链上 制备糖聚肽. 早期的合成方法是将糖分子通过酰胺键直 接化学键合到天然氨基酸(如赖氨酸或谷氨酸)的活性侧 基上(Scheme 3). 由于较低的偶联反应活性及糖基的化 学位阻作用, 糖基元接枝率大多低于 $60 \%$. 采用 1-羟基 苯并三唑(HOBt)或 4-(4,6-二甲氧基三嗪-2-基)-4-甲基吗 啉盐酸盐(DMT-MM) 偶联试剂, 接枝率最高可以达到 $90 \%$ 左右, 但强烈依赖于糖基的化学结构或位阻 ${ }^{[73 ~ 77]}$. 最近, Heise 等 ${ }^{[78]}$ 同样采用 DMT-MM 偶联试剂, 制备了 系列具有精确序列结构的糖聚肽嵌段共聚物, 并研究了 嵌段序列特异性的糖分子在溶液中的二级结构及对凝 集素的特异性识别作用(Scheme 4). 虽然半乳糖分子的 接枝效率达到 90\%～93\%，但非定量的接枝反应仍会对 后续糖聚肽分子的二级结构及生物活性的对比研究产 生影响. 除此之外, Roche $\mathrm{e}^{[79]}$ 和 $\mathrm{Li}$ 等 ${ }^{[80]}$ 采用异硫氰酸根 功能化糖基试剂, 将糖分子通过硫脲键 (Scheme 3c)偶联 到聚氨基酸/多肽侧链上, 该反应即使采用过量的糖基 化试剂，接枝率仍不超过 $40 \%$.

近些年, 随着点击化学在高分子学科领域中的应 用，一系列具有可 “点击” 侧链的聚氨基酸被相继开发 出来，并应用于糖聚肽的制备中. Hammond 等 ${ }^{[81]}$ 于 2009 (a)

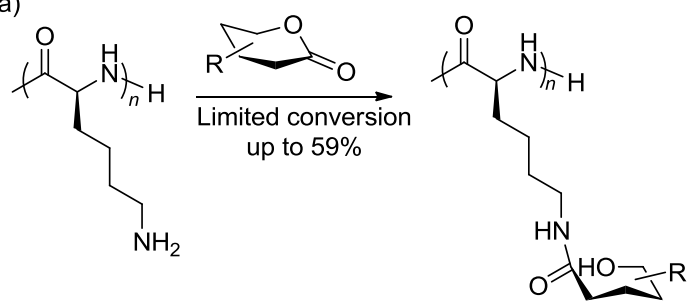

(b)<smiles>[R]CCOC(N)CCC(=O)C(CCC(=O)NC1CCC([R])O1)N=C</smiles>

(c)

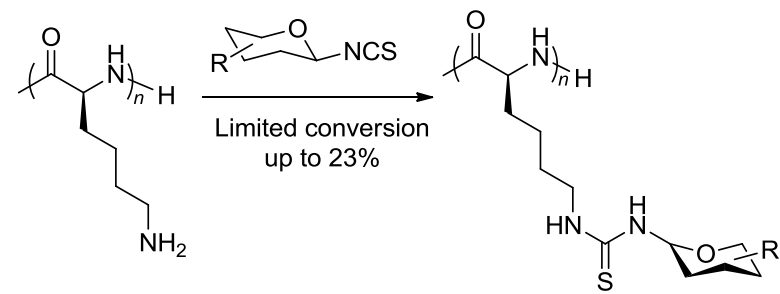

图式 3 采用非点击化学偶联策略在聚氨基酸上接枝糖基元 Scheme 3 Glycosylation onto polypeptide backbones via nonclick chemical coupling approaches

年首次报道了将叠氮化的聚乙二醇(PEG-azides)通过 $\mathrm{Cu}(\mathrm{I})$ 催化的叠氮一炔环加成点击反应偶联到聚 $(\gamma$-炔丙 基- $L$-谷氨酸酯) (PPLG)上，以近乎定量的反应产率制备 得到含有侧挂 PEG 的聚合物分子刷. 随后, Chen 等 ${ }^{[82]}$ 采用同样的聚氨基酸前体 PPLG, 将三种叠氮基功能化 糖分子通过 CuAAC 反应偶联到聚合物主链上，分别制 备得到含有侧挂葡萄糖、半乳糖和甘露糖分子的糖聚肽

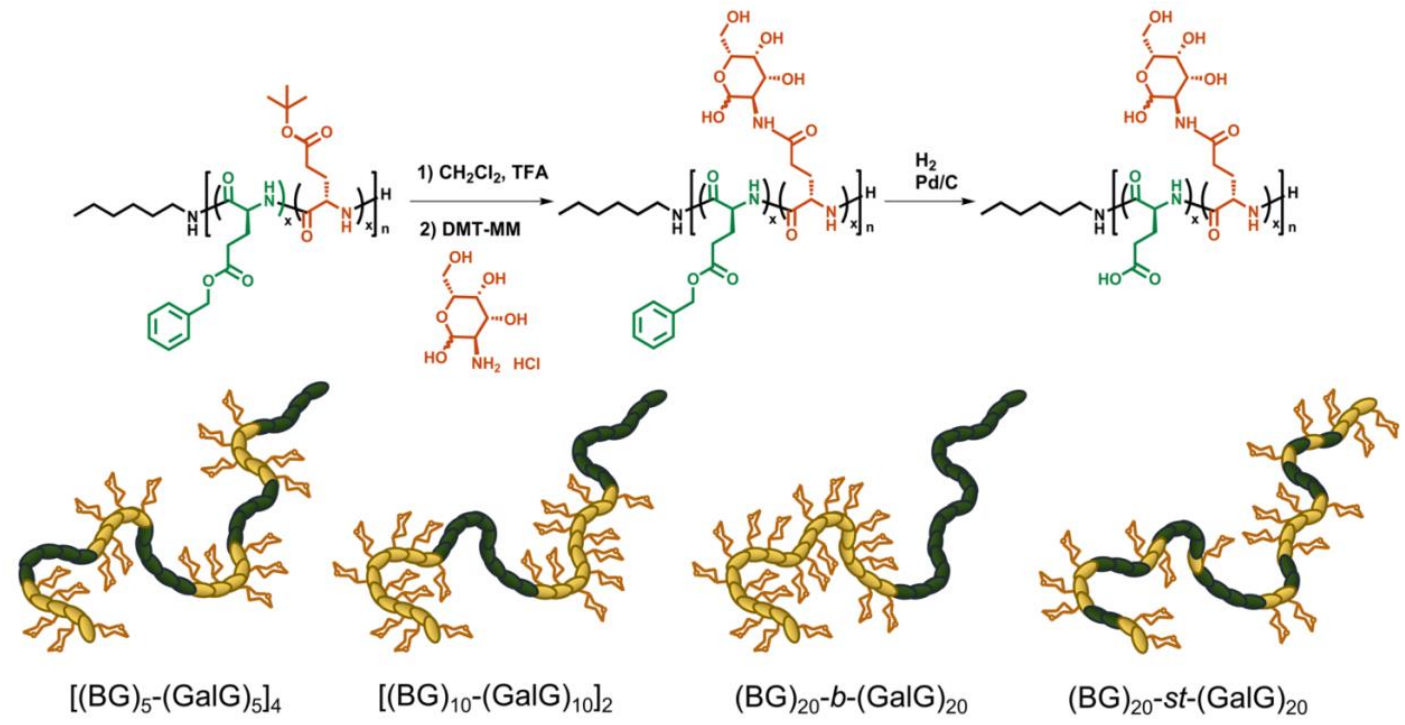

图式 4 系列具有可变一级结构的嵌段序列特异性糖聚肽的合成 ${ }^{[78]}$

Scheme 4 Synthesis of well-defined block-sequence-specific glycopolypeptides with systematically verified primary structure 
(Scheme 5), 拓展了合成糖聚肽的糖基多样性. 该小组 进一步利用此合成策略, 制备了含有侧挂糖基元和 3-(4-羟苯基)-丙酰胺(HPPA)的共聚物作为仿生软骨组 织工程支架 ${ }^{[46]}$, 以及糖聚肽与聚谷氨酸(PLGA) 的嵌段 共聚物作为阿霉素 $(\mathrm{DOX})$ 的高效输送载体 ${ }^{[83]}$. Brougham 等 ${ }^{[84]}$ 以氧化铁纳米颗粒表面的氨基为引发剂, 引发 $\gamma$-炔 丙基- $L$-谷氨酸酯-NCA 单体开环聚合, 再通过 CuAAC 反应高效偶联糖分子, 制备所得糖聚肽修饰磁纳米粒子 具有良好的溶液分散性, 并具有生物识别及磁共振成像 特性, 有望作为磁共振成像造影剂. Heise 等 ${ }^{[85]}$ 采用 $\mathrm{CuAAC}$ 反应, 将半乳糖和二乙二醇单甲醚 $\left(\mathrm{mEO}_{2}\right)$ 同步 偶联到 PPLG 侧链上, 制备了具有温敏特性的糖聚肽. 有趣的是, 该糖聚肽对凝集素 $\mathrm{RCA}_{120}$ 的特异性识别能 力与聚合物溶液的浊点温度有关, 且可以通过半乳糖和 $\mathrm{mEO}_{2}$ 的接枝比例进行调控. 这为温度敏感的生物学响 应功能材料的设计制备提供了新思路. 除此之外, Gupta 等 ${ }^{[86]}$ 制备了两亲均聚糖聚肽, 并研究了其自组装行为. 但是, 上述采用 PPLG 后修饰糖基元的策略虽然可以高 效定量得到功能糖聚肽, 但侧链中酯键在生理条件下会 缓慢水解, 降低糖聚肽的生物活性. 另外, 酯键在强酸 和强碱溶液中均不稳定, 在多种官能团的脱保护基团反 应条件下均会发生断裂, 从而限制了具有较复杂分子结 构和多种功能的糖聚肽体系的进一步制备及应用。

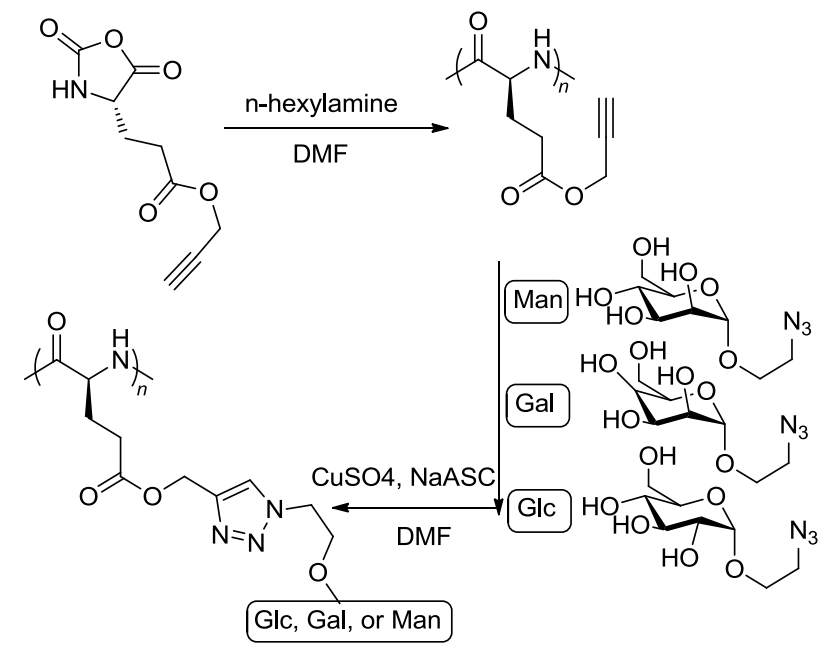

图式 5 Chen 等报道的利用点击反应对聚 $(\gamma$-炔丙基- $L$-谷氨酸 酯)的糖基化策略 ${ }^{[82]}$

Scheme 5 "Click" glycosylation of poly( $\gamma$-propargy- $L$ glutamate) by Chen et al.

基于上述酯键的不稳定性, 为了提高疏水侧链的水 解稳定性, Heise 和 Lecommandoux 等 ${ }^{[87 ~ 90]}$ 合成了炔丙 基甘氨酸-NCA 单体, 并通过一级胺引发的开环聚合反 应制备了聚(炔丙基甘氨酸)均聚物及与 PBLG 的无规和 嵌段共聚物. 随后, 在三乙胺和催化量 $\left(\mathrm{PPh}_{3}\right)_{3} \mathrm{CuBr}$ 的二 甲基亚砜(DMSO)溶剂中, 与叠氮基功能化半乳糖高效
反应，获得具有水解稳定性的系列糖聚肽高分子。该糖 聚肽均聚物 PGG 在溶液中呈现 $\beta$-折叠结构, 并且与凝 集素 $\mathrm{RCA}_{120}$ 具有特异性识别作用, 表现出良好的生物 活性; 同时，两亲嵌段共聚物 PGG- $b$-PBLG 通过 “纳米 沉淀法” 自组装形成球状胶束、蠕虫状胶束和囊泡等多 种形貌聚集体 ${ }^{[38]}$. 随后, Lecommandoux 等 ${ }^{[91]}$ 采用更为 廉价的天然氨基酸替代上述非天然氨基酸制备糖聚肽. 该方法以 $\omega$-氨基叔丁氧羰基(Boc)保护的赖氨酸-NCA 为前体，经开环聚合制备聚氨基酸，脱除 Boc 保护基后， 在碳二亚胺(DCC)的活化作用下， $\omega$-氨基以近乎定量的 产率偶联戊炔酸, 随后通过 $\mathrm{CuAAC}$ 反应高效接枝乳糖 和半乳糖.

另一种策略即是制备侧链含有叠氮基的聚氨基酸 前体，再与炔基功能化糖基元进行 “Click”偶联. Zhang 等 ${ }^{[92]}$ 于 2010 年首次合成了聚 $(\gamma$-氯丙基 $-L$-谷氨酸酯) (PCPLG), 经叠氮化钠处理, 侧链末端氯原子定量转化 为叠氮基，获得含有侧挂叠氮基的聚 $(\gamma$-叠氮丙基- $L$-谷 氨酸酯)(PAPLG), 再通过 CuAAC 反应键合 1-炔丙基$\alpha-D$ - 甘露糖，获得糖聚肽高分子。随后，Deming 和 Rhodes ${ }^{[93]}$ 开发了一种新型的叠氮基功能化的聚氨基酸. 该方法以苄氧羰基 $(\mathrm{CBz})$ 保护的赖氨酸或鸟氨酸为前体, 首先将 $\omega$-氨基转变为叠氮基团, 再以 $\left(\mathrm{PMe}_{3}\right)_{4} \mathrm{Co}$ 为引发 剂, 引发叠氮基功能化的氨基酸-NCA 单体开环聚合, 制备得到序列长度可控的均聚和共聚氨基酸, 进一步通 过 $\mathrm{CuAAC}$ 点击反应与炔基功能化糖分子高效偶联生成 糖聚肽(Scheme 6). 该方法直接引发叠氮基功能化的 $\mathrm{NCA}$ 单体开环聚合, 避免了聚合反应后官能团转化不 完全的缺陷; 并且, 侧链完全由亚甲基组成, 具有优异 的水解稳定性. 除此之外, Jiang 等 ${ }^{\left[{ }^{[94}\right]}$ 合成了 $\gamma$-(2-叠氮乙 基- $L$-谷氨酸酯)-NCA (AELG-NCA)单体，并以含有二硫

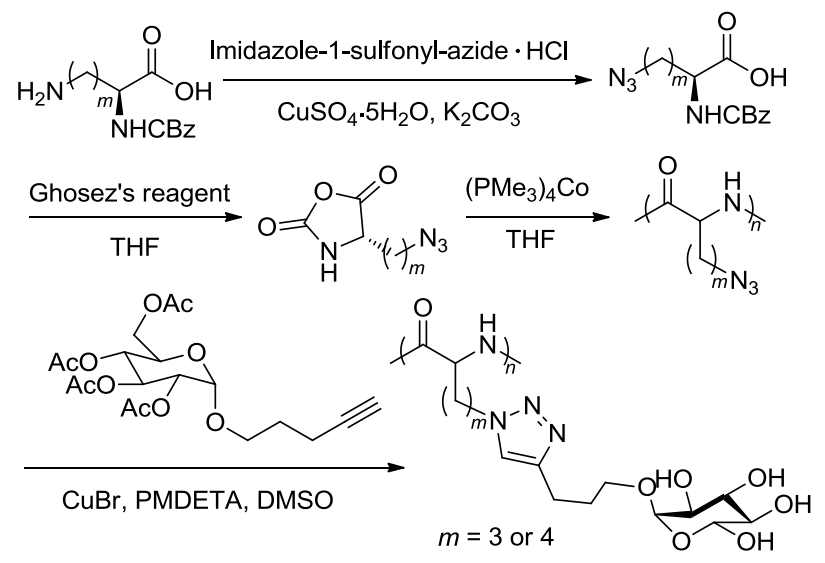

图式 6 采用叠氮基功能化聚氨基酸通过点击反应接枝糖基 元制备糖聚肽 ${ }^{[93]}$

Scheme 6 Preparation of glycopolypeptide via "click" glycosylation with azide bearing polypeptide 
键的氨基封端聚己内酯 PCL-SS- $\mathrm{NH}_{2}$ 引发该 NCA 单体 开环聚合, 后续通过 CuAAC 反应键合乳糖或半乳糖, 制备了具有细胞内还原响应性的两亲嵌段共聚物.

除了 $\mathrm{CuAAC}$ 点击反应外, 近些年, 自由基介导的 “統基- 烯(thiol-ene)” 和 “統基-炔(thiol-yne)” 反应也 被报道应用于制备糖聚肽高分子. 2010 年, Schlaad 等 ${ }^{[95]}$ 首先合成了单分散 $(\mathrm{PDI}<1.10)$ 的聚(烯丙基甘氨酸)及聚 乙二醇-嵌段-聚(烯丙基甘氨酸), 并通过光或者热引发 的 “颈基-烯” 点击化学反应, 以几乎定量的收率得到半 乳糖接枝的糖聚肽高分子. 该过程避免了繁琐的糖分子 保护-脱保护反应, 并且反应过程中不需要使用金属催 化剂 ${ }^{[96]}$. 随后, Schlaad 等 ${ }^{[97,98]}$ 进一步研究了通过 “颈基炔” 反应将颈基功能化糖分子键合到聚(炔丙基甘氨酸) 侧链上制备糖聚肽高分子. 结果表明, 在炔基上键合第 1 个颈基功能化糖分子的效率高于 $90 \%$, 但由于空间位 阻的限制, 第 2 个糖分子接枝效率较低, 即使采用过量
的颈基功能化糖分子，最终偶联的糖分子与炔基物质的 量之比不超过 1.5. 遗憾的是, 聚(烯丙基甘氨酸)和聚 (炔丙基甘氨酸)在常用有机溶剂和水中溶解性均很差, 这限制了高分子量聚氨基酸的合成及后续糖分子接枝 反应的效率.

除此之外, Deming 和 Kramer ${ }^{[99,100]}$ 直接采用天然氨 基酸——甲硫氨酸为原料制备聚 ( $L$-甲硫氨酸), 并在其 侧链通过一种类似于 “点击” 反应的 “甲硫氨酸烷基化” 反应，将含有碘基、三氟甲磺酸酯基或环氧基功能化的 糖分子键合到聚氨基酸侧链上形成糖聚肽高分子. 该反 应直接采用廉价易得的天然氨基酸, 不需要侧链修饰及 基团保护, 并且可以和其它氨基酸进行共聚, 其官能团 对脱保护反应条件等均具有良好的兼容性.

到目前为止, 已有数十种功能聚氨基酸被合成出 来，并通过后续 “点击” 反应制备得到糖聚肽，具体分 子结构在表 1 中表示. 继续丰富和发展可 “点击” 聚氨

表 1 用于制备各种糖聚肽的可点击聚氨基酸及相应糖基元

Table 1 Clickable polypeptides and corresponding saccharide units for the synthesis of glycopolypeptides

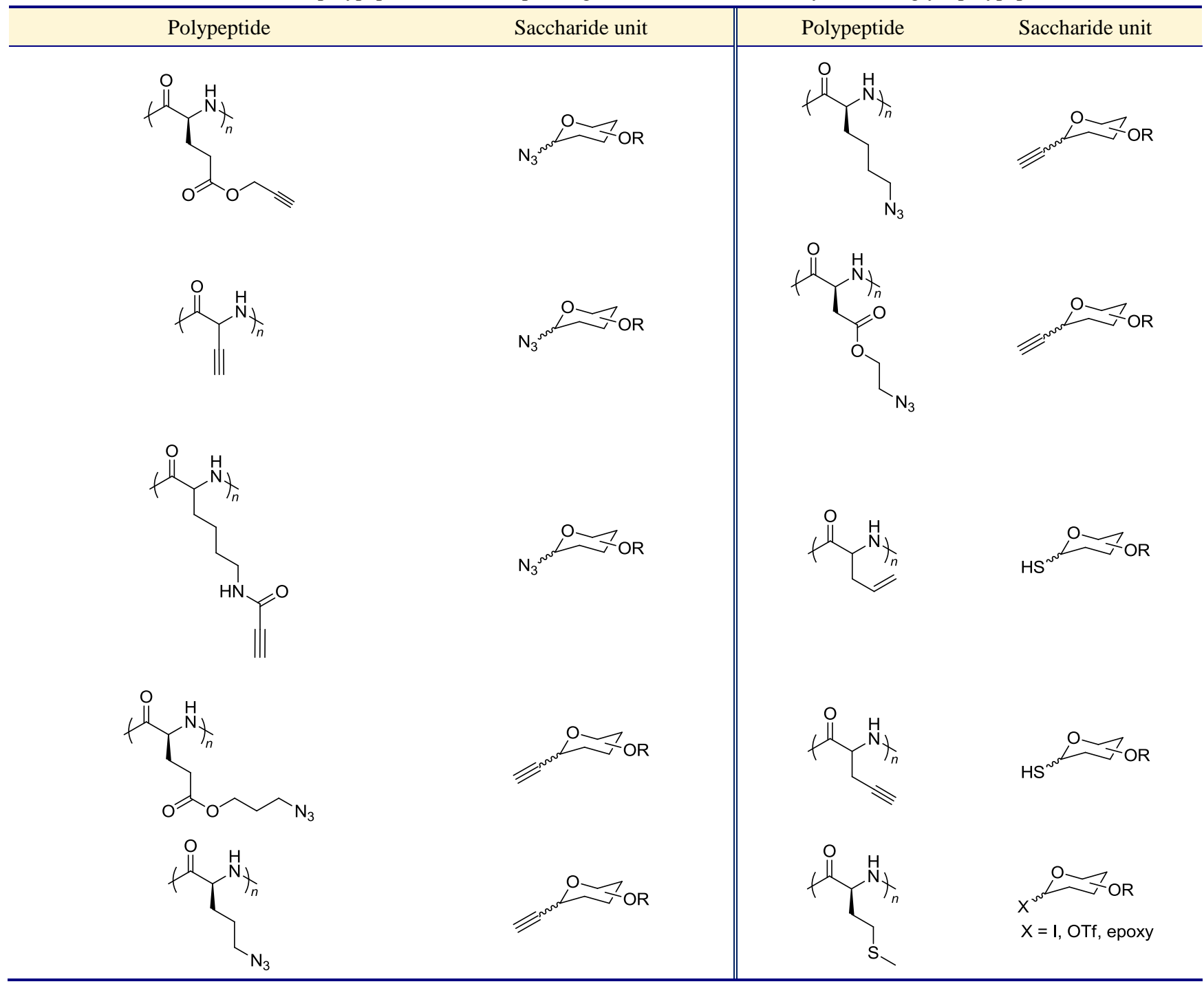


基酸和糖基元的种类，简化合成步骤，提高接枝反应的 效率仍是目前研究的重点.

\section{2 利用点击反应制备含糖 NCA 单体, 再通过开环聚 合制备糖聚肽}

糖聚肽高分子的另一种合成方法是直接利用含糖 $\mathrm{NCA}$ 单体开环聚合. 含糖 NCA 单体的制备和应用可以 追溯到 19 世纪 60 年代. Rüde 等 ${ }^{[101]}$ 在 1966 年首次合成 了含葡萄糖分子的丝氨酸 NCA 单体, 但受限于含糖 $\mathrm{NCA}$ 单体的纯度, 无法开环聚合得到高分子量糖聚肽. 之后虽有含糖 NCA 单体合成方法的陆续报道, 但纯度问 题始终未得到有效解决. 直到 2010 年, Deming 等 ${ }^{[102]}$ 报道 了一种利用快速柱层析法(flash chromatography)对所制 备的含糖赖氨酸-NCA 单体进行纯化的方法, 首次解决 了含糖 NCA 单体纯度较低的问题. 随后, 才有一些含糖 $\mathrm{NCA}$ 单体被合成出来, 并应用到糖聚肽的制备当中.

其中, 点击反应为含糖 NCA 单体的制备提供了新 的思路. 2012 年, Deming 等 ${ }^{[103]}$ 报道了一种以 $L$ - 半胱氨 酸或 $L$-高半胱氨酸为起始原料, 通过 “颈基-烯” 点击 化学方法, 将全乙酰基保护半乳糖或葡萄糖分子高效地 键合到氨基酸上形成氨基酸-糖缀合物 (glyco-Cys NCA), 进一步通过 Leuch 反应进行环合, 快速柱层析分 离后, 得到高纯度糖分子键合的 NCA 单体. 该单体可 以通过 $\left(\mathrm{PMe}_{3}\right)_{4} \mathrm{Co}$ 引发开环聚合, 糖聚肽的链长随单体/ 引发剂比例线性增长, 聚合度最高可以达到 200 , 且分 子量分布较窄 $(\mathrm{PDI}<1.2)$ (Scheme 7). 之后, Schlaad 等 ${ }^{[104]}$ 发展了一种通过 “颈基-烯” 反应直接将颈基功能 化全乙酰基保护半乳糖分子键合到烯丙基甘氨酸 NCA 上, 原位合成含糖 NCA 单体(Scheme 8), 大大简化了含 糖 NCA 单体的制备纯化步骤. 通过控制颈基化糖分子 的接枝比, 开环聚合后可以获得侧基同时含有烯丙基和 糖基元的糖聚肽高分子.

采用含糖 NCA 单体开环聚合制备糖聚肽的方法, 虽然能有效避免聚合后修饰带来的接枝反应不完全的 问题, 但含糖 NCA 单体的制备和纯化是难点, 目前仅 有为数不多的单体被合成出来并成功应用于后续糖聚 肽制备当中, 具体结构如图 4 所示. 因此, 如何利用高 效而便于操作的有机合成反应制备纯化含糖 NCA 单体, 并扩展含糖 NCA 单体的种类是目前研究的重点方向.

\section{3 通过点击反应将糖基元与聚氨基酸/多肽链末端进 行偶联制备糖聚肽类似物}

为克服上述两种聚糖肽合成制备中存在的步骤繁 琐、纯化困难、单体种类有限等不足, 近些年, 科研工 作者尝试通过点击反应将糖基元偶联到聚氨基酸/多肽 链末端制备糖聚肽类似物, 以期进一步拓展糖聚肽及其
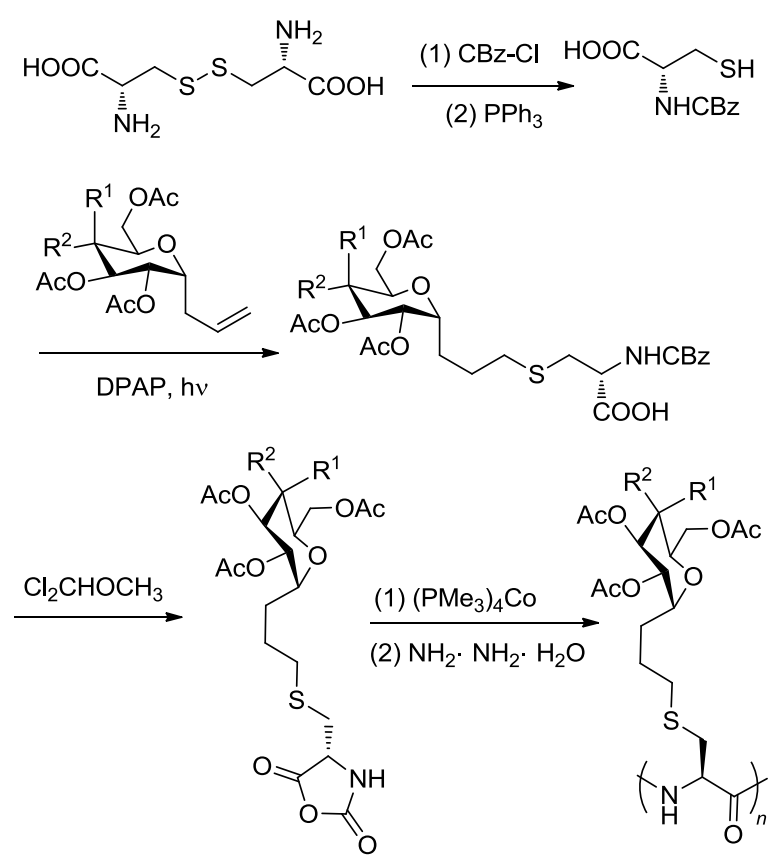

$\alpha$-Gal-Cys: $\mathrm{R}^{1}, \mathrm{R}^{4}=\mathrm{H} ; \mathrm{R}^{2}, \mathrm{R}^{3}=\mathrm{OAc}$ $\alpha$-Glc-Cys: $\mathrm{R}^{1}, \mathrm{R}^{3}=\mathrm{H} ; \mathrm{R}^{2}, \mathrm{R}^{4}=\mathrm{OAc}$

图式 7 Deming 等报道的糖基化-NCA 单体的制备及聚合反 应 $^{[103]}$

Scheme 7 Preparation and polymerization of glycol-NCAs by Deming et al. ${ }^{[103]}$

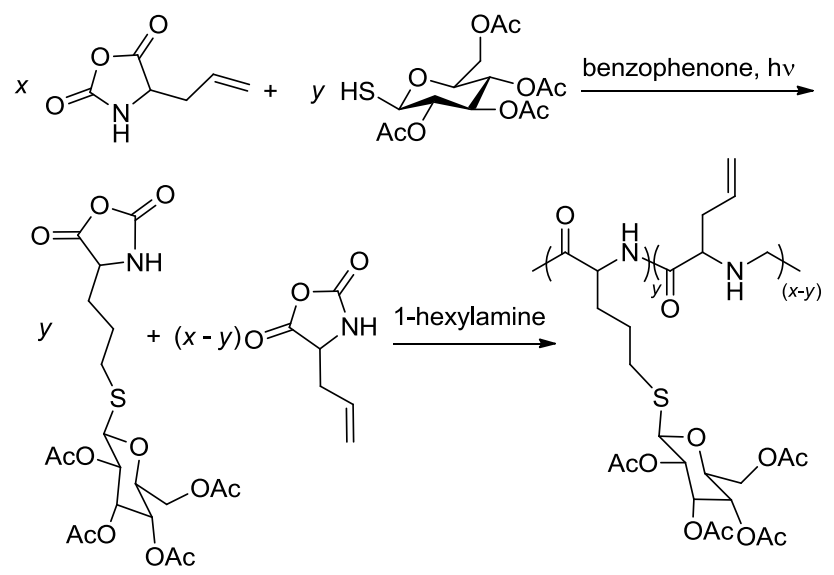

图式 8 “一锅法” 部分糖基化及其与烯丙基甘氨酸环内酸酐 单体的共聚合反应 ${ }^{[104]}$

Scheme 8 "One-pot" partial glycosylation and copolymerization of AGly $\mathrm{NCA}^{[104]}$

类似物的种类. 采用这种方法, 可以有效地将天然单 糖 ${ }^{[105]}$ 、双糖 ${ }^{[106]}$ 、低聚糖、多糖 ${ }^{[37,107,108]}$ 以及人工合成糖 聚合物 ${ }^{[109]}$ 偶联到聚氨基酸/多肽链末端，制备线性、枝 状等不同拓扑结构的聚合物. 这些丰富结构的糖聚肽类 似物, 为糖组学 (Glycomics)的研究以及疾病的诊断和治 疗提供了新途径. 同时，人工合成两亲糖聚肽类似物的 结构和组成更易于进行聚合物亲疏水比例及理化性能 

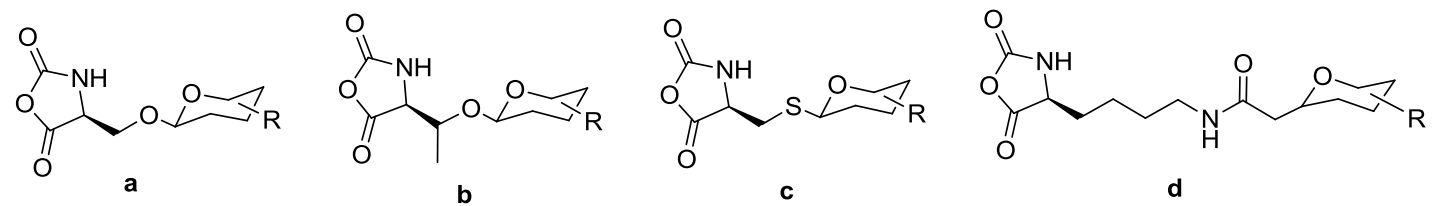<smiles>O=C1COC(CCCSCCCC2COC(=O)N2)C1</smiles><smiles>[R]C1COC(OC(=O)NCCCCC2NC(=O)OC2=O)C1</smiles><smiles>[R]C1CCC(CCCSCC[C@H]2NC(=O)OC2=O)OC1=O</smiles><smiles>[R]C1COC(OCCOC)C1</smiles><smiles>[R]C1CCOC(CCSCC2NC(=O)OC2=O)C1</smiles>

图 4 糖基取代 NCA 单体的化学结构

Figure 4 Chemical structures of sugar-substituted NCA monomers

的调控, 有利于进一步可控制备球形、纤维状及蠕虫状 胶束和囊泡自组装体. Lecommandoux 小组 ${ }^{[37,90,107,110 ~ 112]}$ 首先采用 3 -叠氮丙胺引发 $\gamma$-芐基- $L$-谷氨酸酯-NCA 单体 开环聚合, 得到末端具有叠氮基团的聚( $\gamma$-芐基- $L$-谷氨 酸酯)(PBLG), 再通过 CuAAC 反应将末端炔基功能化 的葡聚糖、透明质酸、半乳聚糖等键合到疏水的 PBLG 末端, 制备得到系列具有两亲性嵌段结构的糖聚肽类似 物. 其中 PBLG 的 $\alpha$-螺旋结构有利于层状结构聚集体的 形成, 且 DOX 负载自组装纳米颗粒表面的透明质酸可 以特异性靶向过表达 CD44 受体的癌细胞.

Wang 等 ${ }^{[109]}$ 运用可逆加成-断裂链转移(RAFT)活性 自由基聚合、NCA 开环聚合和“Click”偶联的组合合成 方法, 制备了含有侧挂半乳糖基和 PBLG 的两亲嵌段共 聚物 PMAgala-SS-PBLG. 首先制备了含有二硫键且末 端叠氮基功能化的 RAFT 链转移剂, 并对丙酮保护的甲 基丙烯酸半乳糖酯单体 MAIpGP 进行聚合, 制备得到叠 氮基功能化的糖聚合物, 再通过 CuAAC 反应和末端炔 基功能化的 PBLG 偶联, 脱除半乳糖保护基后得到目标 聚合物. 该合成策略可以有效调控糖聚合物以及聚氨基 酸嵌段的长度, 在保留半乳糖嵌段生物活性和聚氨基酸 嵌段 $\alpha$-螺旋结构的同时, 界面二硫键的引入可以实现两 亲自组装胶束在 HepG2 肝肿瘤细胞内的还原响应性药 物释放, 有望作为高生物相容性的肝靶向高效药物输送 载体得到进一步应用(Scheme 9).

在具有不同拓扑结构的糖聚肽的制备方面, 也有点 击反应的相关应用报道. $\mathrm{Gu}$ 等 ${ }^{[133}$ 通过 $\mathrm{CuAAC}$ 反应将三 代精氨酸树状大分子成功偶联到乳糖酸修饰的普鲁兰 多糖上, 制备了两亲树状糖聚肽 LP- $g$-G3P, 其负载抗肿 瘤药物 DOX 的自组装复合胶束能特异性抑制肝癌细胞 的增殖. Lecommandoux 等 ${ }^{[114]}$ 首先制备了聚 $(\gamma$-芐基- $L$-谷 氨酸酯) - 嵌段- 聚 $\left(D / L\right.$-炔丙基甘氨酸)(PBLG- $\left.b-\mathrm{PPAG}_{5}\right)$
共聚物，继而在炔基末端通过“Click”策略偶联大分子葡 聚糖，制备了树枝状糖聚肽类似物，并研究了其溶液自 组装行为(图 5). Yan 等 ${ }^{[15]}$ 采用可逆加成-断裂链转移 (RAFT)可控自由基聚合、 $N$-羧基环丙酸䣶(NCA)开环聚 合和“Click”偶联组合方法，制备了两亲多臂共聚物，随 后将近红外苂光探针和 DOX 共价偶联到聚氨基酸嵌段 上. 该大分子药物不仅具有 $\mathrm{pH}$ 响应性和近红外光成像 特性，同时表面接枝的半乳糖分子能通过受体靶向增强 肝细胞的内吞能力. Chan-Park 等 ${ }^{[116]}$ 采用类似的多反应 组合策略, 制备了四臂星状糖聚肽类似物 P(GlyEMA)$\mathrm{P}($ Lys) (Scheme 10). 其中, 聚赖氨酸两臂有抗菌活性, 糖聚合物两臂在提高聚合物对哺乳动物细胞相容性的 同时有效增强同靶向细菌的结合作用. 因而, 采用该聚 合物合成策略制备的四臂糖聚肽类似物，能够有效利用 糖分子和氨基酸独特的生物活性, 为抗菌材料的制备提 供了新思路.

\section{3 结语及展望}

关于糖聚肽合成策略及功能化应用的研究是目前 化学、材料科学及生物医学领域重要的前沿研究方向. 大部分有关糖聚肽合成方法的研究工作均发表于 2010 年以后，且其在生物医用方面的应用也刚刚起步，尚有 大量未知的领域需要探索. 例如, 利用人工合成糖聚肽 深入研究糖蛋白的结构及功能, 仿生模拟天然层状结构 蛋白(如胶原、角蛋白等), 利用糖聚肽对生物活性物质 进行识别、检测、分离和提纯, 调控细胞黏附、诱导细 胞增殖分化等. 这些应用的推进均离不开糖聚肽合成技 术的发展.

点击反应的发展大大促进了糖聚肽的合成制备, 得 益于其具有的反应条件温和、效率高、对功能性基团耐 受性好和产物易于提纯等优点, 已被证实是一种高效实 

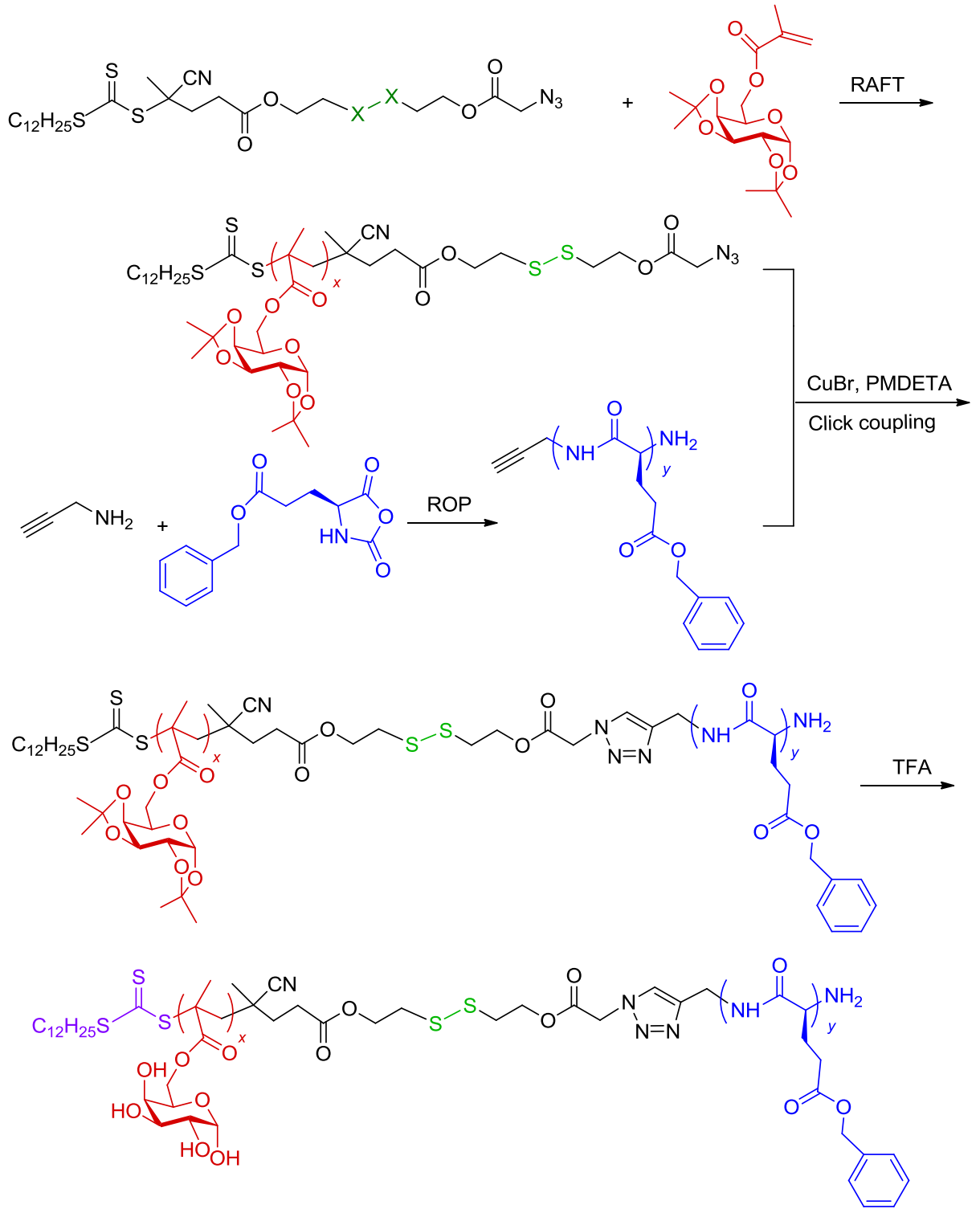

图式 9 还原响应性糖聚肽类似物的制备及其生物识别特性及作为药物输送载体的应用 ${ }^{[109]}$

Scheme 9 Schematic illustration of preparing redox-responsive glycopolypeptide analogues and their biological recognition and drug delivery applications

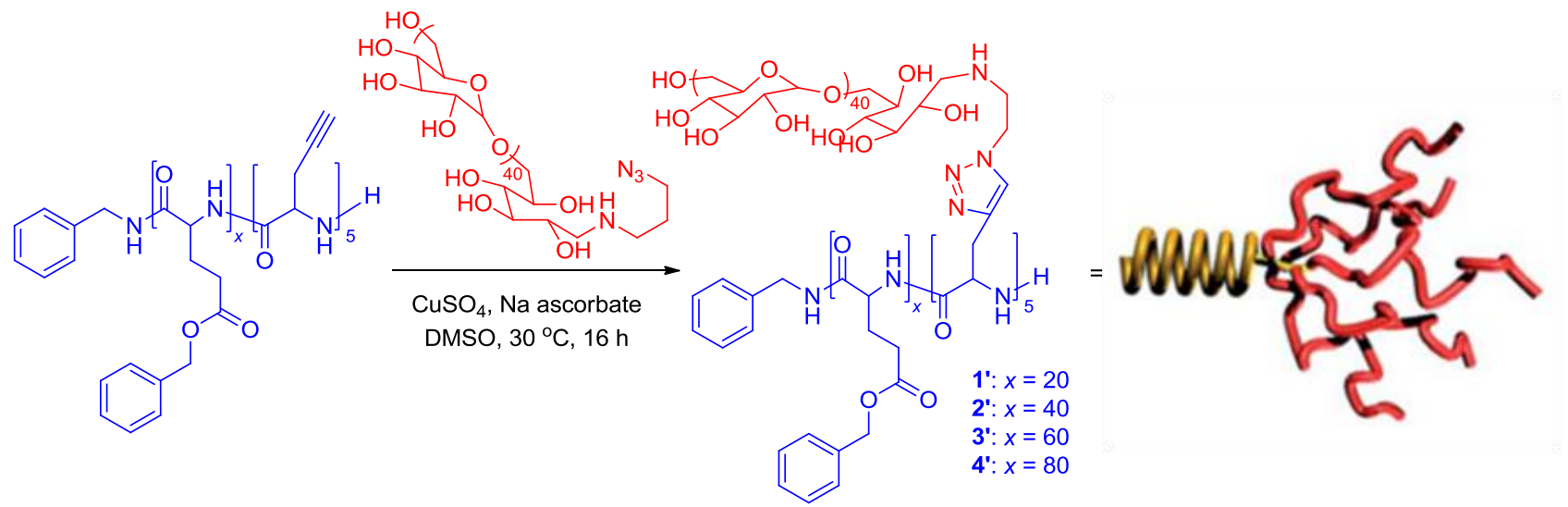

图 5 通过 $\mathrm{CuAAC}$ 点击反应合成树枝状糖聚肽类似物 ${ }^{[114]}$

Figure 5 Synthesis of Oligosaccharide-based branched glycopolypeptide by CuAAC "Click" reaction 

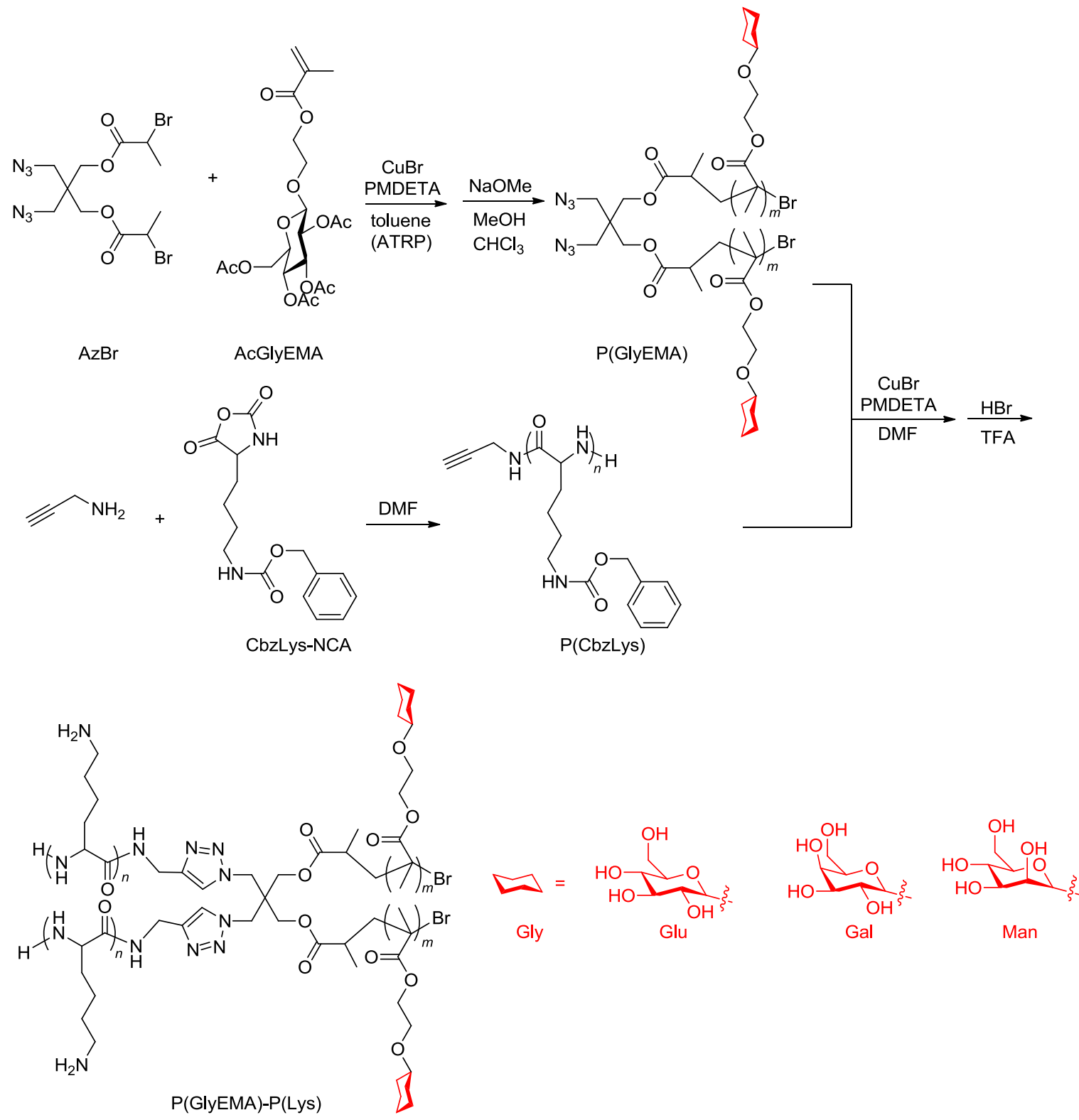

图式 10 通过原子转移自由基聚合(ATRP)、开环聚合和点击化学制备四臂星状糖聚合物-聚肽轭合物 P(GlyEMA)-P(Lys) ${ }^{[116]}$ Scheme 10 Preparation of the four-arm star glycopolymer-polypeptide conjugates P(GlyEMA)-P(Lys) via controlled radical polymerization, ring-opening polymerization, and "Click" chemistry

用的反应. 但是, 采用聚合后修饰法及糖苷化-NCA 单 体开环聚合法制备糖聚肽的策略, 仍然存在接枝反应非 定量、合成纯化步骤繁琐、单体种类有限等不足. 未来, 在基于糖聚肽的合成方面还有很大的发展空间需要开 拓, 主要包括以下几个方面: (1)简化制备路线, 缩短合 成步骤, 发展高效提纯策略; (2)发展更加绿色的点击聚 合反应, 如以水、离子液体作为溶剂, 且无金属催化 (Metal Free)的点击聚合反应, 如光催化反应、有机催化 反应和酶模型催化反应等; (3)开发更加高效、普适、功 能化的(如智能响应和生物活性)单体和与单体相匹配的 点击反应类型, 拓展糖聚肽高分子的种类; (4)合成序列
结构精确可控的糖聚肽高分子; (5)继续制备具有丰富拓 扑结构[如超支化结构、对称/不对称高级结构、大环结 构以及特殊的 3D 结构(如 Janus, Cubic, Origami 和 Inclusion)和理化与生物功能(如分子识别、受体靶向、 膜通道模拟、信号传导和分子伴侣)的糖聚肽. 在此基础 上, 以上述功能糖聚肽作为组装基元, 进一步采用超分 子组装和纳米聚集体可控合成方法, 制备得到基于功能 糖聚肽的仿生纳米组装体, 为其后续的生物医学功能化 应用提供基础.

\section{References}

[1] Bertozzi, C. R.; Kiessling, L. L. Science 2001, 291, 2357. 
[2] Helenius, A.; Aebi, M. Science 2001, 291, 2364.

[3] Miura, Y. Polym. J. 2012, 44, 679.

[4] Kiessling, L. L.; Grim, J. C. Chem. Soc. Rev. 2013, 42, 4476.

[5] Yilmaz, G.; Becer, C. R. Eur. Polym. J. 2013, 49, 3046.

[6] Pratt, M. R.; Bertozzi, C. R. Chem. Soc. Rev. 2005, 34, 58.

[7] Bonduelle, C.; Lecommandoux, S. Biomacromolecules 2013, 14, 2973.

[8] Krannig, K. S.; Schlaad, H. Soft Matter. 2014, 10, 4228.

[9] Xiao, C. S.; Ding, J. X.; He, C. L.; Chen, X. S. Acta Polym. Sin. 2018, 45 (in Chinese).

(肖春生, 丁建勋, 贺超良, 陈学思, 高分子学报, 2018, 45.)

[10] Kempe, K.; Krieg, A.; Becer, C. R.; Schubert, U. S. Chem. Soc. Rev. 2012, 41, 176.

[11] Hu, Q.; Li, Y. X.; Wang, J. Y.; Li, Y. Y. Acta Chim. Sinica 2015, 73, 416 (in Chinese). (胡齐, 李玉祥, 王静媛, 李亚鹏, 化学学报, 2015, 73, 416.)

[12] Kolb, H. C.; Finn, M. G.; Sharpless, K. B. Angew. Chem., Int. Ed. 2001, 40, 2004.

[13] Wang, Z.; Luo, Z. J.; Li, M. R.; Sheng, R. L.; Luo, T.; Cao, A. M. Acta Polym. Sin. 2016, 667 (in Chinese). (王昭, 罗志基, 李明睿, 盛瑞隆, 罗挺, 曹阿民, 高分子学报, 2016, 667.)

[14] Döhler, D.; Michael, P.; Binder, W. H. Acc. Chem. Res. 2017, 50, 2610.

[15] Huang, D.; Liu, Y.; Qin, A.; Tang, B. Z. Polym. Chem. 2018, 9, 2853.

[16] Qin, A.; Liu, Y.; Tang, B. Z. Macromol. Chem. Phys. 2015, 216, 818.

[17] Such, G. K.; Johnston, A. P. R.; Liang, K.; Caruso, F. Prog. Polym. Sci. 2012, 37, 985.

[18] Hoyle, C. E.; Lowe, A. B.; Bowman, C. N. Chem. Soc. Rev. 2010, 39, 1355.

[19] Hoyle, C. E.; Bowman, C. N. Angew. Chem., Int. Ed. 2010, 49, 1540 .

[20] Liu, Q.; Zhang, Q. Y.; Chen, S. J.; Zhou, J.; Lei, X. F. Chin. J. Org. Chem. 2012, 32, 1846 (in Chinese).

(刘清, 张秋禹, 陈少杰, 周健, 雷星锋, 有机化学, 2012, 32, 1846.)

[21] Jiang, Y.; Chen, J.; Deng, C.; Suuronen, E. J.; Zhong, Z. Biomaterials 2014, 35, 4969.

[22] Sowinska, M.; Urbanczyk-Lipkowska, Z. New J. Chem. 2014, 38, 2168.

[23] Martens, S.; Holloway, J. O.; Du Prez, F. E. Macromol. Rapid Commun. 2017, 38, 1.

[24] Lowe, A. B. Polym. Chem. 2014, 5, 4820.

[25] Li, B.; Huang, D.; Qin, A.; Tang, B. Z. Macromol. Rapid Commun. 2018, 39, 1.

[26] Huang, D.; Liu, Y.; Qin, A.; Tang, B. Z. Polym. Chem. 2018, 9, 2853.

[27] Huang, Z. H.; Zhou, Y. Y.; Wang, Z. M.; Li, Y.; Zhang, W.; Zhou, N. C.; Zhang, Z. B.; Zhu, X. L. Chin. J. Polym. Sci. 2017, 35, 317.

[28] Tang, W.; Becker, M. L. Chem. Soc. Rev. 2014, 43, 7013.

[29] Tu, X. Y.; Liu, M. Z.; Wei, H. J. Polym. Sci., Part A: Polym. Chem. 2016, 54, 1447.

[30] Zou, W.; Dong, J.; Luo, Y.; Zhao, Q.; Xie, T. Adv. Mater. 2017, 29 1606100.

[31] Xiong, X. Q.; Yi, C. Sci. Sin. Chim. 2013, 43, 783 (in Chinese). (熊兴泉, 易超, 中国科学: 化学, 2013, 43, 783.)

[32] Huang, D.; Qin, A. J.; Tang, B. Z. Acta Polym. Sin. 2017, 178 (in Chinese).

(黄蝶, 秦安军, 唐本忠, 高分子学报, 2017, 178.)

[33] Bonduelle, C.; Lecommandoux, S. Biomacromolecules 2013, 14, 2973.

[34] Deng, C.; Wu, J.; Cheng, R.; Meng, F.; Klok, H. A.; Zhong, Z. Prog. Polym. Sci. 2014, 39, 330.

[35] Lu, H.; Wang, J.; Song, Z.; Yin, L.; Zhang, Y.; Tang, H.; Tu, C.; Lin, Y.; Cheng, J. Chem. Commun. 2014, 50, 139.

[36] Li, X.; Chen, G. Polym. Chem. 2015, 6, 1417.
[37] Schatz, C.; Louguet, S.; Le Meins, J.-F.; Lecommandoux, S. Angew. Chem., Int. Ed. 2009, 48, 2572.

[38] Huang, J.; Bonduelle, C.; Thévenot, J.; Lecommandoux, S.; Heise, A. J. Am. Chem. Soc. 2012, 134, 119.

[39] Kramer, J. R.; Rodriguez, A. R.; Choe, U.-J.; Kamei, D. T.; Deming, T. J. Soft Matter. 2013, 9, 3389.

[40] Pati, D.; Das, S.; Patil, N. G.; Parekh, N.; Anjum, D. H.; Dhaware, V.; Ambade, A. V.; Sen Gupta, S. Biomacromolecules 2016, 17, 466.

[41] Liu, Y.; Zhang, Y.; Wang, Z.; Wang, J.; Wei, K.; Chen, G.; Jiang, M. J. Am. Chem. Soc. 2016, 138, 12387.

[42] Das, S.; Sharma, D. K.; Chakrabarty, S.; Chowdhury, A.; Sen Gupta, S. Langmuir 2015, 31, 3402.

[43] Pati, D.; Kalva, N.; Das, S.; Kumaraswamy, G.; Sen Gupta, S.; Ambade, A. V. J. Am. Chem. Soc. 2012, 134, 7796.

[44] Stöhr, T.; Blaudszun, A. R.; Steinfeld, U.; Wenz, G. Polym. Chem. 2011, 2, 2239

[45] Ding, J.; Xiao, C.; Li, Y.; Cheng, Y.; Wang, N.; He, C.; Zhuang, X.; Zhu, X.; Chen, X. J. Control. Release 2013, 169, 193.

[46] Ren, K.; He, C.; Xiao, C.; Li, G.; Chen, X. Biomaterials 2015, 51, 238.

[47] Klink, D. T.; Chao, S.; Glick, M. C.; Scanlin, T. F. Mol. Ther. 2001, 3,831 .

[48] Kramer, J. R.; Schmidt, N. W.; Mayle, K. M.; Kamei, D. T.; Wong, G. C. L.; Deming, T. J. ACS Cent. Sci. 2015, 1, 83.

[49] Jacobs, J.; Byrne, A.; Gathergood, N.; Keyes, T. E.; Heuts, J. P. A.; Heise, A. Macromolecules 2014, 47, 7303.

[50] Kramer, J. R.; Onoa, B.; Bustamante, C.; Bertozzi, C. R. Proc. Natl. Acad. Sci. U. S. A. 2015, 112, 12574.

[51] Kramer, J. R.; Deming, T. J. Polym. Chem. 2014, 5, 671.

[52] Hadjichristidis, N.; Iatrou, H.; Pitsikalis, M.; Sakellariou, G. Chem. Rev. 2009, 109, 5528.

[53] Cheng, J.; Deming, T. J. Top. Curr. Chem. 2012, 310, 1.

[54] Brzezinska, K. R.; Deming, T. J. Macromol. Biosci. 2004, 4, 566.

[55] Deming, T. J. Peptide Hybrid Polymers, Berlin, Heidelberg, 2006, pp. $1 \sim 18$

[56] Deming, T. J. Nature 1997, 390, 386

[57] Deming, T. J. J. Am. Chem. Soc. 1998, 120, 4240.

[58] Deming, T. J.; Curtin, S. A. J. Am. Chem. Soc. 2000, 122, 5710

[59] Deming, T. J. Adv. Drug Delivery Rev. 2002, 54, 1145.

[60] Curtin, S. A.; Deming, T. J. J. Am. Chem. Soc. 1999, 121, 7427.

[61] Rhodes, A. J.; Deming, T. J. J. Am. Chem. Soc. 2012, 134, 19463.

[62] Brzezinska, K. R.; Curtin, S. A.; Deming, T. J. Macromolecules 2002, 35, 2970.

[63] Zhao, L.; Li, N.; Wang, K.; Shi, C.; Zhang, L.; Luan, Y. A Biomaterials 2014, 35, 1284.

[64] Shen, Y.; Fu, X.; Fu, W.; Li, Z. Chem. Soc. Rev. 2015, 44, 612.

[65] Wibowo, S. H.; Sulistio, A.; Wong, E. H. H.; Blencowe, A.; Qiao, G. G. Chem. Commun. 2014, 50, 4971.

[66] Cai, C.; Lin, J.; Lu, Y.; Zhang, Q.; Wang, L. Chem. Soc. Rev. 2016, 45, 5985.

[67] Lu, H.; Wang, J.; Song, Z.; Yin, L.; Zhang, Y.; Tang, H.; Tu, C.; Lin, Y.; Cheng, J. Chem. Commun. 2014, 50, 139.

[68] Liarou, E.; Varlas, S.; Skoulas, D.; Tsimblouli, C.; Sereti, E.; Dimas, K.; Iatrou, H. Prog. Polym. Sci. 2018, 83, 28.

[69] Deming, T. J. Chem. Rev. 2016, 116, 786.

[70] Song, Z.; Han, Z.; Lv, S.; Chen, C.; Chen, L.; Yin, L.; Cheng, J. Chem. Soc. Rev. 2017, 46, 6570.

[71] Zhou, X.; Li, Z. Adv. Healthcare Mater. 2018, 7, 1800020.

[72] Wang, M. Z.; Du, J. Z. Acta Polym. Sin. 2014, 1183 (in Chinese). (王明智，杜建忠，高分子学报, 2014, 1183.)

[73] Tian, Z.; Wang, M.; Zhang, A.; Feng, Z. Polymer 2008, 49, 446.

[74] Zeng, X.; Murata, T.; Kawagishi, H.; Usui, T.; Kobayashi, K. Carbohydr. Res. 1998, 312, 209.

[75] Zeng, X.; Murata, T.; Kawagishi, H.; Usui, T.; Kobayashi, K. Biosci. Biotechnol. Biochem. 1998, 62, 1171.

[76] Kobayashi, K.; Tawada, E.; Akaike, T.; Usui, T. Biochim. Biophys. Acta 1997, 1336, 117. 
[77] Mildner, R.; Menzel, H. J. Polym. Sci., Part A: Polym. Chem. 2013, $51,3925$.

[78] Lavilla, C.; Yilmaz, G.; Uzunova, V.; Napier, R.; Becer, C. R.; Heise, A. Biomacromolecules 2017, 18, 1928.

[79] Midoux, P.; Mendes, C.; Legrand, A.; Raimond, J.; Mayer, R.; Monsigny, M.; Roche, A. C. Nucleic Acids Res. 1993, 21, 871.

[80] Wang, R.; Xu, N.; Du, F. S.; Li, Z. C. Chem. Commun. 2010, 46, 3902.

[81] Engler, A. C.; Lee, H.; Hammond, P. T. Angew. Chem., Int. Ed. 2009, 48, 9334.

[82] Xiao, C.; Zhao, C.; He, P.; Tang, Z.; Chen, X.; Jing, X. Macromol. Rapid Commun. 2010, 31, 991.

[83] Ding, J.; Xiao, C.; Li, Y.; Cheng, Y.; Wang, N.; He, C.; Zhuang, X.; Zhu, X.; Chen, X. J. Controlled Release 2013, 169, 193.

[84] Borase, T.; Ninjbadgar, T.; Kapetanakis, A.; Roche, S.; O'Connor, R.; Kerskens, C.; Heise, A.; Brougham, D. F. Angew. Chem., Int. Ed. 2013, 52, 3164.

[85] Kapetanakis, A.; Heise, A. Eur. Polym. J. 2015, 69, 483.

[86] Dhaware, V.; Shaikh, A.; Kar, M.; Hotha, S.; Gupta, S. Langmuir 2013, 29, 5659.

[87] Huang, J.; Habraken, G.; Audouin, F.; Heise, A. Macromolecules 2010, 43, 6050.

[88] Bonduelle, C.; Huang, J.; Ibarboure, E.; Heise, A.; Lecommandoux, S. Chem. Commun. 2012, 48, 8353.

[89] Bonduelle, C.; Huang, J.; Mena-Barragan, T.; Ortiz Mellet, C.; Decroocq, C.; Etame, E.; Heise, A.; Compain, P.; Lecommandoux, S. Chem. Commun. 2014, 50, 3350.

[90] Bonduelle, C.; Oliveira, H.; Gauche, C.; Huang, J.; Heise, A.; Lecommandoux, S. Chem. Commun. 2016, 52, 11251.

[91] Gauche, C.; Lecommandoux, S. Polymer 2016, 107, 474

[92] Tang, H.; Zhang, D. Biomacromolecules 2010, 11, 1585.

[93] Rhodes, A. J.; Deming, T. J. ACS Macro Lett. 2013, 2, 351.

[94] Yang, H. K.; Bao, J. F.; Mo, L.; Yang, R. M.; Xu, X. D.; Tang, W. J.; Lin, J. T.; Wang, G. H.; Zhang, L. M.; Jiang, X. Q. $R S C A d v$. 2017, 7, 21093.

[95] Sun, J.; Schlaad, H. Macromolecules 2010, 43, 4445.

[96] Krannig, K. S.; Sun, J.; Schlaad, H. Biomacromolecules 2014, 15, 978.

[97] Krannig, K. S.; Schlaad, H. J. Am. Chem. Soc. 2012, 134, 18542.
[98] Krannig, K. S.; Huang, J.; Heise, A.; Schlaad, H. Polym. Chem. 2013, 4, 3981.

[99] Kramer, J. R.; Deming, T. J. Biomacromolecules 2012, 13, 1719.

[100] Kramer, J. R.; Deming, T. J. Chem. Commun. 2013, 49, 5144.

[101] Rüde, E.; Westphal, O.; Hurwitz, E.; Fuchs, S.; Sela, M. Immunochemistry 1966, 3, 137.

[102] Kramer, J. R.; Deming, T. J. J. Am. Chem. Soc. 2010, 132, 15068

[103] Kramer, J. R.; Deming, T. J. J. Am. Chem. Soc. 2012, 134, 4112

[104] Krannig, K. S.; Doriti, A.; Schlaad, H. Macromolecules 2014, 47, 2536.

[105] Wang, R.; Xu, N.; Du, F. S.; Li, Z. C. Acta Polym. Sin. 2013, 774 (in Chinese).

(王睿, 许宁, 杜福胜, 李子臣, 高分子学报, 2013, 774.)

[106] Wang, S. S.-S.; How, S.-C.; Chen, Y.-D.; Tsai, Y.-H.; Jan, J.-S. J. Mater. Chem. B 2015, 3, 5220.

[107] Upadhyay, K. K.; Le Meins, J.-F.; Misra, A.; Voisin, P.; Bouchaud, V.; Ibarboure, E.; Schatz, C.; Lecommandoux, S. Biomacromolecules 2009, 10, 2802

[108] Yang, H. K.; Zhang, L. M. Mater. Sci. Eng., C: Mater. Biol. Appl. 2014, 41,36

[109] Wang, Z.; Sheng, R.; Luo, T.; Sun, J.; Cao, A. Polym. Chem. 2017, 8,472 .

[110] Upadhyay, K. K.; Bhatt, A. N.; Castro, E.; Mishra, A. K.; Chuttani, K.; Dwarakanath, B. S.; Schatz, C.; Le Meins, J. F.; Misra, A.; Lecommandoux, S. Macromol. Biosci. 2010, 10, 503.

[111] Upadhyay, K. K.; Mishra, A. K.; Chuttani, K.; Kaul, A.; Schatz, C.; Le Meins, J. F.; Misra, A.; Lecommandoux, S. Nanomedicine 2012, 8,71 .

[112] Upadhyay, K. K.; Bhatt, A. N.; Mishra, A. K.; Dwarakanath, B. S.; Jain, S.; Schatz, C.; Le Meins, J.-F.; Farooque, A.; Chandraiah, G.; Jain, A. K.; Misra, A.; Lecommandoux, S. Biomaterials 2010, 31, 2882.

[113] Mohamed Wali, A. R.; Zhou, J.; Ma, S.; He, Y.; Yue, D.; Tang, J. Z.; Gu, Z. Int. J. Pharm. 2017, 525, 191.

[114] Bonduelle, C.; Mazzaferro, S.; Huang, J.; Lambert, O.; Heise, A.; Lecommandoux, S. Faraday Discuss. 2013, 166, 137.

[115] Fu, L.; Sun, C.; Yan, L. ACS Appl. Mater. Interfaces 2015, 7, 2104.

[116] Pranantyo, D.; Xu, L. Q.; Hou, Z.; Kang, E. T.; Chan-Park, M. B. Polym. Chem. 2017, 8, 3364. 